\title{
Sputum metabolomic profiling revels metabolic pathways and signatures associated with inflammatory phenotypes in patients with asthma
}

\author{
Ying Liu ${ }^{1}$, Xin Zhang ${ }^{1}$, Li Zhang ${ }^{1}$, Brian Oliver ${ }^{2}$, Hong Guang Wang ${ }^{3}$, Zhi Peng Liu ${ }^{3}$, \\ Zhihong Chen ${ }^{4}$, Lisa Wood ${ }^{5}$, Alan $\mathrm{Hsu}^{5}$, Min Xie ${ }^{6}$, Vanessa McDonald ${ }^{5}$, Hua Jing Wan ${ }^{7}$, \\ Feng Ming Luo ${ }^{1}$, Dan Liu ${ }^{1}$, Wei Min $\mathrm{Li}^{1}$, and Gang Wang ${ }^{1}$ \\ ${ }^{1}$ Sichuan University West China Hospital \\ ${ }^{2}$ University of Technology Sydney School of Life Sciences \\ ${ }^{3}$ Biotree-Shanghai Shanghai 201815 China \\ ${ }^{4}$ Zhongshan Hospital Fudan University \\ ${ }^{5}$ The University of Newcastle The Priority Research Centre for Healthy Lungs \\ ${ }^{6}$ Tongji Hospital Department of Hematology \\ ${ }^{7}$ Sichuan University
}

September 24, 2021

\begin{abstract}
Background: The molecular links between metabolism and inflammation that drive different inflammatory phenotypes in asthma are poorly understood. Objectives: To identify the metabolic signatures and underlying molecular pathways of different inflammatory asthma phenotypes. Method: In the discovery set $(n=119)$, untargeted ultra-high performance liquid chromatography-mass spectrometry (UHPLC-MS) were applied to characterize the induced sputum metabolic profiles from asthmatic patients classified by different inflammatory phenotypes using orthogonal partial least-squares discriminant analysis (OPLS-DA) and pathway topology enrichment analysis. In the validation set $(\mathrm{n}=114)$, differential metabolites were selected to perform targeted quantification. Correlations between targeted metabolites and clinical indexes in asthma patients were analyzed. Logistic and negative binomial regression models were established to assess the association between metabolites and severe asthma exacerbation. Results: 77 differential metabolites were identified in the discovery set. Pathway topology analysis uncovered that histidine metabolism, glycerophospholipid metabolism, nicotinate and nicotinamide metabolism, linoleic acid metabolism, phenylalanine, tyrosine and tryptophan biosynthesis were involved in the pathogenesis of different asthma phenotypes. In the validation set, 24 targeted quantification metabolites were significantly differentially expressed between asthma inflammatory phenotypes. Finally, adenosine 5 '-monophosphate $(\operatorname{RRadj}=1.000,95 \% \mathrm{CI}=[1.000,1.000], P=0.050)$, allantoin $(\mathrm{RRadj}=1.000,95 \% \mathrm{CI}=[1.000,1.000], P=0.043)$ and nicotinamide $(\mathrm{RRadj}=1.001,95 \% \mathrm{CI}=[1.000,1.002], P$ $=0.021)$ were demonstrated to predict severe asthma exacerbation rate ratios. Conclusions: Different inflammatory asthma phenotypes have specific metabolic profiles in induced sputum. The potential metabolic signatures may serve as identification and therapeutic target in different inflammatory asthma phenotypes.
\end{abstract}

\section{Introduction}

Asthma is a serious global health problem of chronic inflammatory airway disease, which is characterized by airway hyperresponsiveness and reversible airway obstruction resulting in recurrent episodes of wheezing, shortness of breath, chest tightness, and cough ${ }^{1}$. Asthma is a heterogeneous disease with different phenotypes and endotypes, within which the inflammatory phenotypes of asthma (eosinophilic asthma [EA], neutrophilic 
asthma [NA], and paucigranulocytic asthma [PGA]) are widely recognized by differential proportions of induced sputum granulocytes ${ }^{2}$. Although some guidelines recommend tailored management approaches for patients with different inflammatory phenotypes ${ }^{1,3,4}$, treatment strategy for specific inflammatory phenotypes especially neutrophilic asthma is lacking and represents an unmet medical need in asthma ${ }^{5,6}$ Meanwhile, the molecular mechanisms driving different inflammatory phenotypes asthma are poorly understood and are likely heterogeneous. Therefore, it is important to identify the specific biomarkers and to understand the molecular mechanism of different inflammatory phenotypes of asthma, which may lead to more personalized medicine ${ }^{7}$.

Metabolomics is the systematic identification and quantitation scientific study of chemical processes involving metabolites, small molecule substrates, intermediates and products of cell metabolism in a given organism or biological sample ${ }^{8,9}$. Metabolomics represent an integrated pathophysiological profile encompassing genetic and environmental interactions, which can be instrumental in elucidating the biological mechanisms of asthma. There is growing evidence that metabolomic profiles in exhaled breath condensate (EBC), urine, and blood could distinguish asthma and asthma phenotypes ${ }^{10}$. Our previous study has also showed for the first time that the metabolite profiles in induced sputum better separate asthma phenotypes ${ }^{11}$. Although some studies have shown that inflammatory asthma phenotypes can be discriminated by an electronic nose breath analyzer ${ }^{12}$, there are no specific metabolic biomarkers and molecular pathways identified in terms of different inflammatory asthma phenotypes in the study. Therefore, it can be more justified with the use of induced sputum for studies that aimed at obtaining a close molecular mechanism of different inflammatory asthma phenotypes.

The primary aim of this study was to identify the metabolic signatures and underlying molecular pathways of different inflammatory asthma phenotypes. The secondary aim was to explore if these signatures are related to asthma control and exacerbation. We applied ultra-high performance liquid chromatography-mass spectrometry (UHPLC-MS) to characterize the induced sputum metabolic profiles from healthy controls and asthmatic patients classified by different inflammatory phenotypes as EA, NA and PGA in the discovery set. Following multivariate modelling, the concentrations of selected metabolites were confirmed with targeted mass spectrometry assays in the validation set.

\section{Methods}

Study design and subjects

This study included two parts with the first part as a cross-sectional study to identify the metabolic signatures and underlying molecular pathways of different inflammatory asthma phenotypes and the second part as a prospective cohort study to explore the association between those identified signatures in the first part and asthma exacerbation in the 12 month followed-up. This study included patients with asthma based on the Australasian Severe Asthma Network (ASAN) $)^{13}$. Asthma participants in the discovery set $(n=119)$ of the cross-sectional study and in the validation set $(n=114)$ of the prospective cohort study were recruited from the Asthma Clinic of West China Hospital, Sichuan University, and 20 healthy volunteers were recruited by advertisement between March 2014 and April 2019. All of patients were aged [?] 18 years with stable asthma (no respiratory tract infection and no exacerbation or systemic corticosteroid use in the previous 4 weeks). Asthma was diagnosed according to American Thoracic Society (ATS) guidelines ${ }^{14}$ and Global Initiative for Asthma (GINA) ${ }^{1}$. The subjects were excluded if they were pregnant or breast feeding, had cognitive impairment, current solid organ malignancy. Asthma inflammatory phenotype was assigned based on a sputum eosinophil cutoff of greater than $3 \%$ and a sputum neutrophil cutoff of greater than $61 \%$ (Patients with a sputum proportion of $<61 \%$ neutrophils and $<3 \%$ eosinophils were classified as PGA, with [?] $61 \%$ neutrophils and $<3 \%$ eosinophils classified as NA, with $<61 \%$ neutrophils and [?] $3 \%$ eosinophils classified as EA, respectively) ${ }^{2}$. This study was reviewed and approved by the institutional review board of West China Hospital, Sichuan University (Chengdu, China) (No.2014-30), and all subjects provided written informed consent.

Clinical assessment 
Data on demographics and clinical characteristics were collected using standardized case report form and detailed were shown in the Online Data Supplement. Asthma Control Questionnaire (ACQ) score ${ }^{15}$, and Asthma Quality of Life Questionnaire (AQLQ) score ${ }^{16}$, were analyzed in all participants. In the validation set, asthma-related exacerbations in the 12 month follow-up were recorded according to the ATS/European Respiratory Society (ERS) guidelines ${ }^{17}$

Sputum induction, processing and airway inflammatory cytokine assay

Sputum induction and processing were performed based on standard methods as described in our previous studies ${ }^{18,19}$. Additional details are described in the Online Data Supplement. In the validation set, sputum supernatant cytokines, regarded as airway inflammatory biomarkers, including IL-1 $\beta$, IL-5, IL-8, IL-13, IL-17A, IFN- $\gamma$, and TNF- $\alpha$, were detected using a Luminex-based MILLIPLEX MAP Human Cytokine/Chemokine Magnetic Bead Panel Kit (EMD Millipore Corporation, Billerica, Mass) with the MILLIPLEX Analyst 5.1 software. Spiking experiments on cytokines in sputum supernatants showed that recovery ranged from $70 \%$ to $130 \%$ in all detectable analyses ${ }^{20,21}$

Ultra high performance liquid chromatography-mass spectrometry method for metabolomics

In the discovery set, the collected sputum supernatant samples were thawed on ice, and metabolites were extracted with acetonitrile and methanol using previously described method ${ }^{22,23}$. Sputum supernatant samples were analyzed through using an UHPLC system (1290, Agilent Technologies) with a UPLC BEH Amide $(2.1 \mathrm{~mm} \times 100 \mathrm{~mm}, 1.7 \mu \mathrm{m})$ coupled to TripleTOF 6550+6600 (Q-TOF, AB Sciex) via a previously described method with modifications ${ }^{24}$. The detailed sputum preparation, spectrometry method and metabolite identification were described in the Online Data Supplement.

Univariate and multivariate analysis for metabolomic profiling

After high-throughput screening of the metabolic features using the above rules, a total of 772 (473 from positive ion mode and 299 from negative ion mode). For each metabolite peak reproducibly detected in whole samples, the unpaired two-tailed Wilcoxon rank-sum test (a nonparametric univariate method) was carried out to measure the significance of each metabolite among different groups and adjusted by false discovery rate (FDR) correction (Benjamini-Hochberg method). The merged UHPLC-MS data were log-transformed for subsequent analyses. The filtered and normalized data matrix was exported for multivariate statistical analysis using principal component analysis (PCA) and orthogonal partial least-squares discriminant analysis (OPLS-DA) with SIMCA 16.1 software package (Umetrics, Umea, Sweden). To further validate the model, the permutation tests $(\mathrm{n}=200)$ was proceeded. By combining the univariate and multivariate statistical analysis, on the basis of a variable importance in the projection (VIP) threshold of 1 from the 10-fold crossvalidated OPLS-DA model, fold change $<0.83$ or $>1.2$, FDR $<0.05$, numbers of different metabolites among different groups were obtained.

Pathway analysis

Metabolomics Pathway Analysis (MetPA) had been performed by online tool MetaboAnalyst with hypergeometric test for over-representation analysis and relative-betweeness centrality for pathway topology analysis ${ }^{25}$

\section{Targeted quantification in the validation set}

After untargeted metabolomics analysis, 40 differential metabolites were selected to perform quantification in patients in the validation set. Metabolites were assayed in multiple reaction monitoring (MRM) mode by LC-MS/MS using an EXION LC System (SCIEX) coupled with SCIEX 6500 QTRAP + Triple Quadrupole mass spectrometry (SCIEX). Details were described in the supplementary material.

Statistics analysis

Continuous variables were expressed as the mean \pm standard deviation or median (quartiles $[\mathrm{Q}] 1,[\mathrm{Q}] 3$ ) depending on their distribution. Categorical variables are summarized as numbers and percentages. For continuous variables, the differences among different inflammatory asthma phenotypes and healthy were 
analyzed using A student's t-test, or ANOVA if they were normally distributed, otherwise Wilcoxon ranksum test were used to assess. Categorical data were compared using the chi-squared test or Fisher's test. Correlations between targeted metabolites and clinical indexes in asthma patients in the validation set were expressed using Spearman's correlation coefficients and adjusted by false discovery rate (FDR) correction (Benjamini-Hochberg method). Between two groups, targeted metabolites were examined by receiver operating characteristic (ROC) curves and the area under the curve (AUC) of each ROC was calculated to show their capability of discriminating different groups in validation set. Logistic and negative binomial regression models were established to assess the association between metabolites and severe asthma exacerbation during follow-up in the validation set. These analyses were conducted using SPSS version 25.0 (IBM Corp, Armonk, NY, USA). In all statistical analyses, a double tailed $P$-value of $<0.05$ was considered statistically significant.

\section{Results}

Demographics and Clinical characteristics

Characteristics of the participants are summarized in Table 1 and Table E1-2. There were 20 healthy control subjects and 119 asthma patients (40 patients with EA, 36 patients with NA and 43 patients with PGA) recruited in the discovery set and 114 asthma patients (35 patients with EA, 30 patients with NA and 49 patients with PGA) recruited in the validation set. Detail demographics and clinical characteristics were described in the Online Data Supplement.

In the validation set, sputum supernatant cytokines, regarded as airway inflammatory biomarkers were assessed. Amongst the asthma phenotypes, patients with EA had the highest level of IL-5 and the lowest levels of TNF- $\alpha$, IL-1 $\beta$, IL-8 (all $P<0.05$ ). However, patients with NA had the highest IL- $1 \beta$ and the lowest IL-5 levels (all $P<0.05$ ) (Table 1). In the 12 month follow-up, there were 3(10\%) patients with NA and 3(6.1\%) PGA who were loss to follow-up. Finally, there were 108 patients with asthma (EA, n=35; $\mathrm{NA}, \mathrm{n}=27$; PGA, $\mathrm{n}=46$ ) were included in the analysis with asthma exacerbations. As a result, there were significant difference in proportions of patients experiencing severe asthma exacerbation (EA vs NA vs PGA: $17.1 \%$ vs $37 \%$ vs $6.5 \%, P=0.004$ ) and severe asthma exacerbation times (EA vs NA vs PGA: $0.29 \pm 0.75$ vs $0.70 \pm 1.33$ vs $0.09 \pm 0.35, P=0.004$ ) between these phenotypic groups (Table 1 ).

\section{Untargeted metabolic profiles discriminate between different inflammatory asthma phenotypes and healthy subjects in the discovery set}

The score plot of OPLS-DA analysis showed a distinct separation between different asthma phenotypes and the Asthma group was also clearly separated from the Healthy group (Figure 1). The parameters for the classification models from the software were showed in the Table E3, suggesting all of the model had a very good fitness and predictive capability. Furthermore, a leave-one-out cross-validation (LOOCV) was used to estimate the robustness and predictive ability of each model, and thus a 200 permutation test was applied. The low value of the $\mathrm{Q}^{2}$ intercept in each model indicated the robustness of these model and thus showed a low risk of over-fitting in all of the comparison.

By combining the univariate and multivariate statistical analysis, on the basis of a variable importance in the projection (VIP) threshold of 1 from the 10-fold cross-validated OPLS-DA model, fold change $<0.83$ or $>1.2, \mathrm{FDR}<0.05$, a total of 77 differential metabolites were screened between different asthma phenotypes and healthy subjects as shown in the heatmap in the Figure 2.

\section{Pathway topology analysis in the discovery set}

To analyze the most relevant pathways after identifying differential metabolites, the metabolic pathway topology enrichment analysis was applied with the impact value to evaluate the importance of the pathways underlying the pathophysiology mechanism in different asthma phenotypes and healthy subjects (Figure 3). As a result, histidine metabolism $(P=0.019$; impact value $=0.189)$ was identified between asthma patients and healthy subjects. Differential metabolites between EA and NA were involved in glycerophospholipid metabolism $(P=0.015$; impact value $=0.121)$, nicotinate and nicotinamide metabolism $(P=0.020$; impact 
value $=0.332)$ and histidine metabolism $(P=0.022$; impact value $=0.189)$. Differential metabolites between EA and PGA were involved in glycerophospholipid metabolism $(P=0.001$; impact value $=0.186)$, linoleic acid metabolism $(P=0.001 ;$ impact value $=1.000)$, histidine metabolism $(P=0.014 ;$ impact value $=0.189)$ and phenylalanine, tyrosine and tryptophan biosynthesis $(P=0.046$; impact value $=0.500)$. Differential metabolites between NA and PGA were involved in linoleic acid metabolism $(P=0.002$; impact value $=$ $1.000)$, glycerophospholipid metabolism $(P=0.010$; impact value $=0.160)$ and nicotinate and nicotinamide metabolism $(P=0.015$; impact value $=0.332)$.

Targeted quantification of identified metabolites between different inflammatory asthma phenotypes and healthy subjects in the validation set

To validate and determine the expression levels of 40 differentially expressed metabolites, which were selected to perform targeted quantification in patients in the validation set. Amongst which, 24 metabolites were significantly differentially expressed between asthma inflammatory phenotypes (Table 2), with 9 of these metabolites reaching a significant $P$ value of .001 or less. Histamine expression was highest but levels of 5 -Lglutamyl-L-alanine, nicotinamide, dihydrothymine, L-leucine, L-phenylalanine, alanyl-leucine, phenylalanylserine, phenylalanylphenylalanine were the lowest in patients with EA. Expression levels of adenosine 5'monophosphate, glyceric acid, taurine, dihydrothymine, L-leucine, tyramine, L-glutamate, alanyl-leucine, phenylalanyl-serine, threoninyl-phenylalanine were highest but level of glycerophosphocholine was lowest in patients with NA. Expression levels of glycerophosphocholine, cyclohexylamine, heptadecanoic acid, oleic acid were highest but level of dodecanoic acid was lowest in patients with PGA (Table 2).

Furthermore, those differentially expressed metabolites were examined by receiver operating characteristic (ROC) curves to discriminate different inflammatory asthma phenotypes (Table E4). As a result, taurine, alanyl-leucine, phenylalanyl-serine and threoninyl-phenylalanine could be used as a candidate metabolite marker to discriminate between NA and EA or PGA with the AUC was range from 0.816 to 0.975 (all $P<$ 0.05). However, no single metabolite could satisfactorily discriminate between EA and PGA as all of the $\mathrm{AUC}<0.7$.

\section{Correlations of differential metabolites with clinical and inflammatory profiles in the validation set}

Correlations analysis showed that differentially expressed metabolites correlated to lung function, asthma control and inflammatory profiles in all subjects with asthma (Figure 3 and Table E5) with the detail in the Online Data Supplement.

We explored the association between metabolites and severe asthma exacerbation during the 12 month follow-up using logistic regression and negative binomial regression models (Table E6). As a result, adenosine 5'-monophosphate was significantly associated with severe asthma exacerbation (Table 3). Adenosine 5 '-monophosphate had increased rate ratios of proportions of patients experiencing severe asthma exacerbation $($ RRadj $=1.000,95 \% \mathrm{CI}=[1.000,1.000], P=0.050)$ and had increased rate ratios of severe asthma exacerbation times $(\mathrm{RRadj}=1.000,95 \% \mathrm{CI}=[1.000,1.000], P=0.008)$ after adjusting for age, gender, $\mathrm{BMI}$ and $\mathrm{FEV}_{1} \%$. In addition, allantoin and nicotinamide both had increased rate ratios of severe asthma exacerbation times $(\mathrm{RRadj}=1.000,95 \% \mathrm{CI}=[1.000,1.000], P=0.043$, and $\mathrm{RRadj}=1.001,95 \% \mathrm{CI}=[1.000$, $1.002], P=0.021$, respectively)

\section{Discussion}

To our knowledge, this is the first study that establishes the metabolic signatures and underlying molecular pathways of different inflammatory asthma phenotypes in induced sputum sample by combing untargeted and targeted metabolomics. This study demonstrated that the unique metabolic profiles that existed between different inflammatory asthma phenotypes and healthy subjects with 77 differential metabolites identified. Pathway topology analysis uncovered that 5 pathways could be involved in the pathogenesis of different asthma phenotypes. Further, 24 targeted quantification metabolites were validated significantly differentially expressed between asthma inflammatory phenotypes, which significantly correlated to clinical and 
inflammatory profiles. Finally, adenosine 5'-monophosphate, allantoin and nicotinamide were shown to predict rate ratios of severe asthma exacerbations. These findings indicated novel immunometabolic mechanisms in different asthma phenotypes, with providing more phenotypic and therapeutic implications.

There have been many metabolomics studies on the difference between asthmatics and healthy subjects or on distinct asthma severity have been performed extensively ${ }^{10,26}$. As for the metabolome research on infammatory phenotype, some studies have shown that inflammatory asthma phenotypes can be discriminated by an electronic nose breath analyzer ${ }^{12}$. Brinkman et $\mathrm{al}^{27}$ further demonstrated that inflammatory phenotypes of severe asthma could be identified by unbiased clustering of exhaled breath profiles using eNose technology. However, eNose technology seems to be suitable for the noninvasive identification of asthma inflammatory phenotypes but is principally unable to identify the individual metabolic pathway and metabolites driving the distinction between the subgroups.

This current study unraveled that histidine metabolism, glycerophospholipid metabolism, nicotinate and nicotinamide metabolism, linoleic acid metabolism, and phenylalanine, tyrosine and tryptophan biosynthesis were involved in the pathogenesis of different asthma phenotypes. In fact, previous studies supported our results as histidine metabolism was identified as implicated pathway between asthma and healthy subjects ${ }^{28}$, and glycerophospholipid metabolism was also participated in the pathogenesis of asthma, especially EA ${ }^{29,} 30$. In addition, linoleic acid metabolism was the most significant pathway between NA and EA or PGA (all impact value $=1, P<0.05$ ), which indicated that the important role of linoleic acid metabolism in the NA. Panda et al. ${ }^{31}$ had proved that linoleic acid metabolite leads to steroid resistant asthma features partially through NF- $x \mathrm{~B}$. Therefore, it is speculated that the development of targeted treatment of linoleic acid metabolism has important implications for the individualized treatment of NA.

Notably, it found that differential metabolites correlated to clinical and inflammatory profiles. Adenosine5'-monophosphate was related with poor asthma control and severe asthma exacerbation. The discovery that adenosine-5'-monophosphate levels are increased in the bronchoalveolar lavage fluid of patients with asthma and increase further after allergen challenge raises the possibility that the adenosine generated in asthmatic airways itself contributes to the pathogenesis of asthma ${ }^{32,33}$. It is possible that the recruitment and activation of inflammatory cells and subsequent smooth muscle contraction that occur during asthma exacerbation leads to an increase in oxygen and energy demand, thus leading to an increase in the level of adenosine in the airway in asthma ${ }^{34}$. We also demonstrated for the first time that allantoin and nicotinamide were involved in severe asthma exacerbation. The roles of these metabolites in asthma pathogenesis and clinical outcomes of asthma remain unknown and further studies are required to their involvement in asthma.

As for the inflammation markers, histamine was significantly related to FeNO and IL-5. Histamine has been shown to play a key role in the pathogenesis of a variety of allergic diseases, including allergic asthma ${ }^{35}$. Except for the partial expression of histamine by immune cells such as basophil ${ }^{36}$, mast cells are the main source of histamine expression and express a large number of different receptors on their cell surface, such as,FceR1, Fc $\gamma R I$, complement receptors (C3AR and C5AR), and ligand receptors such as neurotrophic factor, substance $\mathrm{P}$, vasoactive intestinal peptide, and adenosine phosphate ${ }^{37-40}$. These ligand and allergens can activate mast cells to release the pro-inflammatory mediators including histamine. Furthermore, histamine has been shown to promote $\mathrm{T}_{\mathrm{H}}$ cell differentiation and the release of type 2 inflammatory factors such as IL-5. Consistently, antihistmine has been demonstrated to significantly reduce the risk of emergency visit and hospitalization for asthma, especially in asthmatic patients with other allergic diseases, such as allergic rhinitis ${ }^{41,42}$. Therefore, antihistamine therapy may be considered as an additive treatment for eosinophilic asthma, as it is often associated with allergic diseases such as allergic rhinitis, as also found in current study.

Various amino acids and amino acid dipeptides such as taurine, alanyl-leucine were significantly correlated to TNF- $\alpha$, IL-1 $\beta$, IL-8 and IL-17, which indicated that these differential metabolites may play a very important role in the development of NA. For example, Taurine, a $\beta$-amino acid that is not integrated into proteins, is highly expressed in the intracellular chambers of most tissues. Taurine has been reported to be increased in bronchoalveolar lavage fluid in asthmatic patients ${ }^{43,}$. ${ }^{4}$ I has been shown shown that plasma taurine is formed with arachidonic acid in asthmatic patients ${ }^{45}$ Animal studies have also shown that branching-chain amino 
acids valine, leucine and isoleucine mediated asthma-related airway inflammation through lipid oxidation pathways ${ }^{46}$. Notably, this study also found a number of amino dipeptides that had not been reported in previous studies, and their differential expression were closely related to neutrophilic asthma. Because induced sputum specimens are biological specimens of open airway, they do not simply reflect the changes of human metabolism, but also may reflect the changes of local airway microenvironment, including local microbiota and human host. In fact, recent studies have shown a significant correlation between neutrophilic asthma and airway microbiology ${ }^{47}$. Therefore, this study illustrated important differences of these amino acid dipeptides may reflect the metabolic characteristics of airway microorganisms of NA, and the analysis combined with microbiology may provide us with further scientific evidence.

This study has several limitations to be addressed. First, an external validation in a new cohort was lacking. However, the differential metabolites were validated by exploring the relationships of differential metabolites with clinical and inflammation profiles of asthma in an independent cohort population would strengthen the results. Second, as for the unavailability of reference standards, some of the identified metabolites in the discovery set are undetected, which somewhat limits the exploring of the potential metabolic signature.

In conclusion, different inflammatory asthma phenotypes have specific metabolic profiles with 77 differential metabolic signatures and 5 underlying molecular pathways identified. These metabolic pathways identified involve the histidine metabolism, glycerophospholipid metabolism, nicotinate and nicotinamide metabolism, linoleic acid metabolism, phenylalanine, tyrosine and tryptophan biosynthesis. Differential metabolites identified correlate to clinical and inflammatory profiles of asthma, which may serve as potential therapeutic target in different inflammatory asthma phenotypes.

\section{ACKNOWLEDGMENTS}

The authors are grateful to Ms Michelle Gleeson (Hunter Medical Research Institute, University of Newcastle, Australia), Ms Dan Wang (West China Hospital, Sichuan University, China), and Ms Zhi Lin (West China Hospital, Sichuan University, China) for their blood and sputum processing, and to all patients who volunteered for this study.

\section{Author's contributions}

GW and YL conceived the study, performed the data interpretation and manuscript revision, and took accountability for all aspects of the work. YL, XZ, LZ, HGW, ZPL planned the work, carried out the data analysis and interpretation. YL drafted the manuscript. YL, XZ, LZ and GW conducted the participant recruitment. BGO, ZHC, LW, ACYH, MX, VM, WML, DL, FML, HJW interpreted the results and contributed to the manuscript revision. All authors approved the final manuscript.

\section{Conflict of interest}

The authors declare that they have no conflicts of interest to disclose.

\section{Reference}

1. Global Initiative for Asthma. Global Strategy for Asthma Management and Prevention. 2021. Available from www.ginasthma.org. Accessed July 2021.

2. Simpson JL, Rodney S, Boyle MJ, Gibson PG. Inflammatory subtypes in asthma: assessment and identification using induced sputum. Respirology. 2006;11(1):54-61.

3. British Thoracic Society. British guideline on the management of asthma. Thorax. 2014;69 Suppl 1:1-192.

4. Lougheed MD, Lemiere C, Ducharme FM, Licskai C, Dell SD, Roweet BH, et al. Canadian Thoracic Society 2012 guideline update: diagnosis and management of asthma in preschoolers, children and adults. Can Respir J, 2012, 19(2):127-164.

5. Corren, J, Lemanske RF, Hanania NA, Korenblat PE, Parsey MV, Arron JR, et al. Lebrikizumab treatment in adults with asthma. N Engl J Med. 2011;365(12):1088-98. 
6. Ortega HG, Yancey SW, Mayer B, Gunsoy NB, Keene ON, Bleecker ER, et al. Severe eosinophilic asthma treated with mepolizumab stratified by baseline eosinophil thresholds: a secondary analysis of the DREAM and MENSA studies. Lancet Respir Med. 2016; 4(7):549-556.

7. Bruce DL, Patricia JN, Michelle MF, Cloutier MM, Georas SN, Jarjouret NN, et al. Future Research Directions in Asthma. An NHLBI Working Group Report. Am J Respir Crit Care Med. 2015;192(11):1366-72.

8. Idle JR, Gonzalez FJ. Metabolomics. Cell Metab. 2007;6(5):348-51.

9. Dunn WB, Broadhurst DI, Atherton HJ, Goodacre R, Griffin JL. Systems level studies of mammalian metabolomes: the roles of mass spectrometry and nuclear magnetic resonance spectroscopy. Chem Soc Rev. 2011;40(1):387-426.

10. Kelly RS, Dahlin A, McGeachie MJ, Qiu W, Sordillo J, Wan ES, et al. Asthma Metabolomics and the Potential for Integrative Omics in Research and the Clinic. Chest. 2017;151(2):262-277.

11. Liu Y, Zheng J, Zhang HP, Zhang X, Wang L, Wood L, et al. Obesity-Associated Metabolic Signatures Correlate to Clinical and Inflammatory Profiles of Asthma: A Pilot Study. Allergy Asthma Immunol Res. 2018;10(6):628-647.

12. Plaza V, Crespo A, Giner J, Merino JL, Ramos-Barbón D, Mateus EF, et al. Inflammatory Asthma Phenotype Discrimination Using an Electronic Nose Breath Analyzer. J Investig Allergol Clin Immunol. 2015;25(6):431-7.

13. Wang G, Wang F, Gibson PG, Guo M, Zhang WJ, Gao P, et al. Severe and uncontrolled asthma in China: a cross-sectional survey from the Australasian Severe Asthma Network. J Thorac Dis. 2017 ;9(5):1333-1344.

14. Crapo RO, Casaburi R, Coates AL, Enright PL, Hankinson JL, Irvin CG, et al. Guidelines for methacholine and exercise challenge testing-1999. This official statement of the American Thoracic Society was adopted by the ATS Board of Directors, July 1999. Am J Respir Crit Care Med. 2000; 161(1):309329.

15. Jia CE, Zhang HP, Lv Y, Liang R, Jiang YQ, Powell H, et al. The Asthma Control Test and Asthma Control Questionnaire for assessing asthma control: systematic review and meta-analysis. J Allergy Clin Immunol. 2013;131:695-703.

16. Xu KF, Luo XC, Chen Y, Zhang YJ, Li Y, Hu B, et al. The use of Juniper's asthma quality of life questionnaire in Chinese asthmatics. Zhonghua Nei Ke Za Zhi 2003;42:760-3.

17. Reddel HK, Taylor DR, Bateman ED, Boulet LP, Boushey HA, Busse WW, et al. American Thoracic Society/European Respiratory Society Task Force on Asthma Control and Exacerbations. An official American Thoracic Society/ European Respiratory Society statement: asthma control and exacerbations: standardizing endpoints for clinical asthma trials and clinical practice. Am J Respir Crit Care Med. 2009; 180 (1):59-99.

18. Wang G, Baines KJ, Fu JJ, Wood LG, Simpson JL, McDonald VM, et al. Sputum mast cell subtypes relate to eosinophilia and corticosteroid response in asthma. Eur Respir J. 2016;47(4):1123-33.

19. Deng K, Zhang X, Liu Y, Zhang L, Wang G, Feng M, et al. Heterogeneity of Paucigranulocytic Asthma: A Prospective Cohort Study with Hierarchical Cluster Analysis. J Allergy Clin Immunol Pract. 2021;9(6):2344-2355.

20. Manise M, Holtappels G, Van Crombruggen K, Schleich F, Bachert C, Louis R. Sputum IgE and cytokines in asthma: relationship with sputum cellular profile. PLoS One. 2013;8(3):e58388.

21. Pedersen F, Holz O, Lauer G, Quintini G, Kiwull-Schöne H, Kirsten AM, et al. Multi-analyte profiling of inflammatory mediators in COPD sputum-the effects of processing. Cytokine. 2015;71(2):401-4.

22. Dunn WB, Broadhurst D, Begley P, Zelena E, Francis-McIntyre S, Anderson N, et al; Human Serum Metabolome (HUSERMET) Consortium. Procedures for large-scale metabolic profiling of serum and plasma using gas chromatography and liquid chromatography coupled to mass spectrometry. Nat Protoc. 2011;6(7):1060-83.

23. Contrepois K, Wu S, Moneghetti KJ, Hornburg D, Ahadi S, Tsai MS, et al. Molecular Choreography of Acute Exercise. Cell. 2020;181(5):1112-1130.e16.

24. Wang J, Zhang T, Shen X, Liu J, Zhao D, Sun Y, et al. Serum metabolomics for early diagnosis of 
esophageal squamous cell carcinoma by UHPLC-QTOF/MS. Metabolomics. 2016;12(7):116.

25. Chong J, Soufan O, Li C, Caraus I, Li S, Bourque G, et al. MetaboAnalyst 4.0: towards more transparent and integrative metabolomics analysis. Nucl. Acids Res. 2018;46(W1):W486-W494.

26. Turi KN, Romick-Rosendale L, Ryckman KK, Hartert TV. A review of metabolomics approaches and their application in identifying causal pathways of childhood asthma. J Allergy Clin Immunol. 2018;141(4):1191-1201.

27. Brinkman P, Wagener AH, Hekking PP, Bansal AT, Maitland-van der Zee AH, Wang Y, et al; UBIOPRED Study Group. Identification and prospective stability of electronic nose (eNose)-derived inflammatory phenotypes in patients with severe asthma. J Allergy Clin Immunol. 2019;143(5):18111820.e7.

28. Motta A, Paris D, D'Amato M, Melck D, Calabrese C, Vitale C, et al. NMR metabolomic analysis of exhaled breath condensate of asthmatic patients at two different temperatures. J Proteome Res. 2014;13(12):6107-20.

29. Wang S, Tang K, Lu Y, Tian Z, Huang Z, Wang M, et al. Revealing the role of glycerophospholipid metabolism in asthma through plasma lipidomics. Clin Chim Acta. 2021;513:34-42.

30. Pang Z, Wang G, Wang C, Zhang W, Liu J, Wang F. Serum Metabolomics Analysis of Asthma in Different Inflammatory Phenotypes: A Cross-Sectional Study in Northeast China. Biomed Res Int. 2018;2018:2860521.

31. Panda L, Gheware A, Rehman R, Yadav MK, Jayaraj BS, Madhunapantula SV, et al. Linoleic acid metabolite leads to steroid resistant asthma features partially through NF- $\varkappa$ B. Sci Rep. 2017;7(1):9565.

32. Driver AG, Kukoly CA, Ali S, Mustafa SJ. Adenosine in bronchoalveolar lavage fluid in asthma. Am Rev Respir Dis. 1993;148(1):91-7.

33. Mann JS, Holgate ST, Renwick AG, Cushley MJ. Airway effects of purine nucleosides and nucleotides and release with bronchial provocation in asthma. J Appl Physiol. 1986;61(5):1667-76.

34. van den Berge M, Polosa R, Kerstjens HA, Postma DS. The role of endogenous and exogenous AMP in asthma and chronic obstructive pulmonary disease. J Allergy Clin Immunol. 2004;114(4):737-46.

35. Berla TE, Angel JE, Himadri S, Baig MS, Khan M, Mathias CB, et al. The Role of Histamine and Histamine Receptors in Mast Cell-Mediated Allergy and Inflammation: The Hunt for New Therapeutic Targets. Frontiers in Immunology. 2018; 9:1873.

36. Saluja R, Ketelaar ME, Hawro T, Church MK, Maurer M, Nawijn MC. The role of the IL-33/IL-1RL1 axis in mast cell and basophil activation in allergic disorders. Mol Immunol. 2015;63(1):80-5.

37. Metz M, Siebenhaar F, Maurer M. Mast cell functions in the innate skin immune system. Immunobiology. 2008; 213(3):251-260.

38. Saito H. Mast cell research. Chem Immunol Allergy. 2014;100:165-71.

39. Metcalfe DD, Baram D, Mekori YA. Mast cells. Physiol Rev. 1997;77(4):1033-79.

40. Tatemoto K, Nozaki Y, Tsuda R, Konno S, Tomura K, Furuno M, et al. Immunoglobulin E-independent activation of mast cell is mediated by Mrg receptors. Biochem Biophys Res Commun. 2006;349(4):13228.

41. Adams RJ, Fuhlbrigge AL, Finkelstein JA, Weiss ST. Intranasal steroids and the risk of emergency department visits for asthma. J Allergy Clin Immunol. 2002;109(4):636-42.

42. Corren J, Manning BE, Thompson SF, Hennessy S, Strom BL. Rhinitis therapy and the prevention of hospital care for asthma: a case-control study. J Allergy Clin Immunol. 2004;113(3):415-9.

43. Santangelo F, Cortijo J, Morcillo E. Taurine and the lung: which role in asthma? Adv Exp Med Biol. 2003;526:403-10.

44. Hofford JM, Milakofsky L, Pell S, Fish JE, Peters SP, Pollice M, et al. Levels of amino acids and related compounds in bronchoalveolar lavage fluids of asthmatic patients. Am J Respir Crit Care Med. 1997;155(2):432-5.

45. Comhair SA, McDunn J, Bennett C, Fettig J, Erzurum SC, Kalhan SC. Metabolomic Endotype of Asthma. J Immunol. 2015;195(2):643-50.

46. Bazzano M, Laghi L, Zhu C, Magi GE, Serri E, Spaterna A, et al. Metabolomics of tracheal wash samples and exhaled breath condensates in healthy horses and horses affected by equine asthma. J 
Breath Res. 2018;12(4):046015.

47. Taylor SL, Leong LEX, Choo JM, Wesselingh S, Yang IA, Upham JW, et al. Inflammatory phenotypes in patients with severe asthma are associated with distinct airway microbiology. J Allergy Clin Immunol. 2018;141(1):94-103.e15.

\begin{tabular}{|c|c|c|c|c|c|}
\hline Table 1 & Table 1. & Table 1. & Table 1. & Table 1. & Table 1. \\
\hline $\begin{array}{l}\text { Clinical } \\
\text { characteristics }\end{array}$ & $\begin{array}{l}\text { Clinical } \\
\text { characteristics }\end{array}$ & Clinical & Clinical & Clinical & Clinical \\
\hline $\begin{array}{l}\text { cnaracteristics } \\
\text { grouped by } \\
\text { airway }\end{array}$ & $\begin{array}{l}\text { cnaracteristics } \\
\text { grouped by } \\
\text { airway }\end{array}$ & $\begin{array}{l}\text { characteristics } \\
\text { grouped by } \\
\text { airway }\end{array}$ & $\begin{array}{l}\text { characteristics } \\
\text { grouped by } \\
\text { airway }\end{array}$ & $\begin{array}{l}\text { characteristics } \\
\text { grouped by } \\
\text { airway }\end{array}$ & $\begin{array}{l}\text { characteristics } \\
\text { grouped by } \\
\text { airway }\end{array}$ \\
\hline inflammation & inflammation & inflammation & inflammation & inflammation & inflammation \\
\hline $\begin{array}{l}\text { phenotypes in } \\
\text { the validation }\end{array}$ & $\begin{array}{l}\text { phenotypes in } \\
\text { the validation } \\
\text { set }\end{array}$ & $\begin{array}{l}\text { phenotypes in } \\
\text { the validation } \\
\text { set }\end{array}$ & $\begin{array}{l}\text { phenotypes in } \\
\text { the validation } \\
\text { set }\end{array}$ & $\begin{array}{l}\text { phenotypes in } \\
\text { the validation } \\
\text { set }\end{array}$ & $\begin{array}{l}\text { phenotypes in } \\
\text { the validation } \\
\text { set }\end{array}$ \\
\hline Variables & $\mathrm{EA}$ & $\mathrm{NA}$ & PGA & $\chi^{2} / \Phi / Z$ & $P$ value \\
\hline $\mathrm{n}$ & 35 & 30 & 49 & & \\
\hline Female, n (\%) & $24(68.6)$ & 19(63.3) & $24(49)$ & 3.584 & 0.167 \\
\hline Age, yrs & $45.37 \pm 10.58$ & $51.94 \pm 13.34^{\mathrm{b}}$ & $44.10 \pm 12.08^{\mathrm{d}}$ & 4.220 & 0.017 \\
\hline $\mathrm{BMI}, \mathrm{kg} / \mathrm{m}^{2}$ & $23.68 \pm 2.86$ & $23.28 \pm 3.78$ & $24.63 \pm 4.13$ & 1.404 & 0.250 \\
\hline $\begin{array}{l}\text { Family history, } \\
\mathrm{n}(\%)\end{array}$ & $10(28.6)$ & $14(46.7)$ & $15(30.6)$ & 2.844 & 0.241 \\
\hline Age onset, yrs & $34.00(8.00,42.00)$ & $\begin{array}{l}39.00(22.50, \\
50.75)\end{array}$ & $\begin{array}{l}33.00(16.50, \\
39.50)\end{array}$ & 3.050 & 0.218 \\
\hline $\begin{array}{l}\text { Asthma } \\
\text { duration, yrs }\end{array}$ & $\begin{array}{l}11.62(3.31, \\
35.26)\end{array}$ & $\begin{array}{l}10.92(4.61 \\
22.22)\end{array}$ & $\begin{array}{l}10.21(4.06 \\
20.42)\end{array}$ & 0.661 & 0.719 \\
\hline $\begin{array}{l}\text { Severe asthma, } \\
\mathrm{n}(\%)\end{array}$ & $3(8.6)$ & $5(16.7)$ & $5(10.2)$ & 1.170 & 0.557 \\
\hline BDP, ug & $200(80,400)$ & $400(400,1000)$ & $400(0,800)$ & 12.516 & 0.002 \\
\hline LTRA, n (\%) & $15(42.9)$ & $10(33.3)$ & $18(36.7)$ & 0.659 & 0.719 \\
\hline $\begin{array}{l}\text { Theophylline, } \\
\mathrm{n}(\%)\end{array}$ & $3(8.6)$ & $10(33.3)$ & $11(22.4)$ & 6.060 & 0.048 \\
\hline $\begin{array}{l}\text { Exacerbation } \\
\text { in previous } 12 \\
\text { months,n }(\%)\end{array}$ & $14(40)$ & $11(36.7)$ & $15(30.6)$ & 0.835 & 0.659 \\
\hline $\begin{array}{l}\text { Atopic } \\
\text { comorbidity }\end{array}$ & & & & & \\
\hline $\begin{array}{l}\text { Anaphylactic } \\
\text { rhinitis, n(\%) }\end{array}$ & $23(65.7)$ & $9(31)$ & $25(51)$ & 7.642 & 0.022 \\
\hline Eczema, n(\%) & $7(20)$ & $8(26.7)$ & $8(16.3)$ & 1.236 & 0.539 \\
\hline $\mathrm{SPT}, \mathrm{n}(\%)$ & $16(45.7)$ & $12(40)$ & $23(46.9)$ & 7.790 & 0.100 \\
\hline $\mathrm{ACQ}$ & $\begin{array}{l}0.50(0.17 \\
1.83)\end{array}$ & $\begin{array}{l}0.83(0.33, \\
1.33)\end{array}$ & $\begin{array}{l}0.33(0.00, \\
1.17)\end{array}$ & 4.533 & 0.103 \\
\hline AQLQ & $\begin{array}{l}5.63(4.87 \\
6.42)\end{array}$ & $\begin{array}{l}5.90(5.28 \\
6.42)\end{array}$ & $\begin{array}{l}6.13(5.58 \\
6.59)\end{array}$ & 3.471 & 0.176 \\
\hline $\begin{array}{l}\text { Pre- } \\
\text { bronchodilator }\end{array}$ & $\mathrm{r}$ & & & & \\
\hline $\mathrm{FEV}_{1}, \mathrm{~L}$ & $2.02 \pm 0.61$ & $1.74 \pm 0.57$ & $2.45 \pm 0.98 \mathrm{~b}, \mathrm{c}$ & 8.370 & $<0.001$ \\
\hline $\mathrm{FEV}_{1}, \%$ pred & $69.69 \pm 19.41$ & $63.73 \pm 20.05$ & $77.39 \pm 20.64 \mathrm{c}$ & 4.477 & 0.013 \\
\hline FVC, L & $3.19 \pm 0.73$ & $2.83 \pm 0.63$ & $3.46 \pm 1.10 \mathrm{c}$ & 4.730 & 0.011 \\
\hline FVC, $\%$ & $91.77 \pm 17.75$ & $85.07 \pm 12.451$ & $91.88 \pm 17.02$ & 1.930 & 0.150 \\
\hline $\mathrm{FEV}_{1} / \mathrm{FVC}, \%$ & $63.00 \pm 11.02$ & $61.57 \pm 15.43$ & $70.07 \pm 12.90 \mathrm{~b}, \mathrm{c}$ & 4.972 & 0.009 \\
\hline
\end{tabular}




\begin{tabular}{|c|c|c|c|c|c|}
\hline $\begin{array}{l}\text { Post- } \\
\text { bronchodilator }\end{array}$ & & & & & \\
\hline $\mathrm{FEV}_{1}, \mathrm{~L}$ & $2.29 \pm 0.61$ & $1.89 \pm 0.64 \mathrm{~b}$ & $2.61 \pm 0.88 \mathrm{c}$ & 8.236 & $<0.001$ \\
\hline $\mathrm{FEV}_{1}, \%$ & $73.79 \pm 18.85$ & $68.44 \pm 19.37 \mathrm{~b}$ & $84.30 \pm 17.05 \mathrm{c}$ & 6.749 & 0.002 \\
\hline FVC, L & $3.39 \pm 0.70$ & $3.01 \pm 0.67$ & $3.56 \pm 0.98 \mathrm{c}$ & 3.811 & 0.025 \\
\hline $\begin{array}{l}\text { FVC, \% } \\
\text { BDR }\end{array}$ & $99.16 \pm 15.99$ & $89.36 \pm 10.56 \mathrm{a}$ & $95.99 \pm 13.62 \mathrm{~d}$ & 3.995 & 0.021 \\
\hline$\Delta \mathrm{FEV}_{1}, \mathrm{~L}$ & $\begin{array}{l}0.29(0.16 \\
0.46)\end{array}$ & $\begin{array}{l}0.17(0.05 \\
0.25) \mathrm{a}\end{array}$ & $\begin{array}{l}0.15(0.04 \\
0.32) \mathrm{a}\end{array}$ & 10.118 & 0.006 \\
\hline$\Delta \mathrm{FEV}_{1}, \%$ & $\begin{array}{l}18.06(7.30 \\
29.06)\end{array}$ & $\begin{array}{l}10.68(3.47, \\
18.25) \mathrm{b}\end{array}$ & $\begin{array}{l}6.80(1.27 \\
17.08) \mathrm{a}\end{array}$ & 9.364 & 0.009 \\
\hline FeNO, ppb & $\begin{array}{l}53.50(38.50 \\
79.75)\end{array}$ & $\begin{array}{l}26.50(17.75 \\
49.25) \mathrm{b}\end{array}$ & $\begin{array}{l}29.50(14.25 \\
49.75) \mathrm{b}\end{array}$ & 14.470 & 0.001 \\
\hline $\operatorname{IgE}, \mathrm{IU} / \mathrm{mL}$ & $\begin{array}{l}\text { 119.71(46.80, } \\
378.21)\end{array}$ & $\begin{array}{l}88.76(26.16, \\
391.25)\end{array}$ & $\begin{array}{l}82.83(4547, \\
347.16)\end{array}$ & 0.871 & 0.647 \\
\hline $\begin{array}{l}\text { Sputum } \\
\text { cytology }\end{array}$ & & & & & \\
\hline Total cell & $0.30(0.4,0.42)$ & $\begin{array}{l}0.68(0.42, \\
1.23)\end{array}$ & $\begin{array}{l}0.26(0.13, \\
0.54)\end{array}$ & 24.495 & $<0.001$ \\
\hline Eosinophil, \% & $\begin{array}{l}14.63(7.44, \\
38.75)\end{array}$ & $\begin{array}{l}0.00(0.00 \\
0.25) \mathrm{a}\end{array}$ & $\begin{array}{l}0.00(0.00 \\
0.38) \mathrm{a}\end{array}$ & 78.829 & $<0.001$ \\
\hline $\begin{array}{l}\text { Eosinophil, } \\
\times 10^{4} / \mathrm{mL}\end{array}$ & $\begin{array}{l}4.24(1.50 \\
10.66)\end{array}$ & $\begin{array}{l}0.00(0.00 \\
0.16)\end{array}$ & $\begin{array}{l}0.00(0.00 \\
0.08)\end{array}$ & 74.370 & $<0.001$ \\
\hline Neutrophil, \% & $\begin{array}{l}26.00(13.00, \\
43.00)\end{array}$ & $\begin{array}{l}90.25(78.50, \\
98.31) \mathrm{a}\end{array}$ & $\begin{array}{l}17.75(6.75 \\
35.25) \mathrm{b}, \mathrm{c}\end{array}$ & 67.844 & $<0.001$ \\
\hline $\begin{array}{l}\text { Neutrophil, } \\
\times 10^{4} / \mathrm{mL}\end{array}$ & $\begin{array}{l}5.55(2.97 \\
12.83)\end{array}$ & $\begin{array}{l}57.33(32.13, \\
107.30)\end{array}$ & $\begin{array}{l}3.80(1.32 \\
11.19)\end{array}$ & 57.524 & $<0.001$ \\
\hline $\begin{array}{l}\text { Lymphocyte, } \\
\%\end{array}$ & $\begin{array}{l}1.00(0.50, \\
1.50)\end{array}$ & $\begin{array}{l}0.50(0.25 \\
0.75) \mathrm{b}\end{array}$ & $\begin{array}{l}0.75(0.25 \\
2.00) \mathrm{d}\end{array}$ & 6.245 & 0.044 \\
\hline $\begin{array}{l}\text { Lymphocyte, } \\
\times 10^{4} / \mathrm{mL}\end{array}$ & $\begin{array}{l}0.24(0.05 \\
0.41)\end{array}$ & $\begin{array}{l}0.30(0.10 \\
0.53)\end{array}$ & $\begin{array}{l}0.25(0.06, \\
0.65)\end{array}$ & 0.510 & 0.775 \\
\hline $\begin{array}{l}\text { Macrophage, } \\
\%\end{array}$ & $\begin{array}{l}48.13(28.75 \\
66.63)\end{array}$ & $\begin{array}{l}8.63(1.38 \\
19.31) \mathrm{a}\end{array}$ & $\begin{array}{l}80.50(63.75, \\
92.00) \mathrm{a}, \mathrm{c}\end{array}$ & 76.359 & $<0.001$ \\
\hline $\begin{array}{l}\text { Macrophage, } \\
\times 10^{4} / \mathrm{mL} \\
\text { Sputum } \\
\text { cytokines }\end{array}$ & $\begin{array}{l}11.04(8.01 \\
19.08)\end{array}$ & $\begin{array}{l}5.85(1.05, \\
12.57)\end{array}$ & $\begin{array}{l}21.60(8.32, \\
39.80)\end{array}$ & 23.856 & $<0.001$ \\
\hline $\mathrm{TNF}-\alpha, \mathrm{pg} / \mathrm{mL}$ & $\begin{array}{l}\text { 6.13(2.67, } \\
13.12)\end{array}$ & $\begin{array}{l}32.58(5.53, \\
58.27) \mathrm{a}\end{array}$ & $\begin{array}{l}\text { 12.24(5.07, } \\
26.46) \mathrm{a}\end{array}$ & 13.398 & $<0.001$ \\
\hline $\mathrm{IFN}-\gamma, \mathrm{pg} / \mathrm{mL}$ & $\begin{array}{l}2.01(1.80, \\
2.77)\end{array}$ & $\begin{array}{l}2.18(1.90 \\
2.44)\end{array}$ & $\begin{array}{l}2.01(1.66 \\
2.631)\end{array}$ & 0.631 & 0.729 \\
\hline $\mathrm{IL}-1 \beta, \mathrm{pg} / \mathrm{mL}$ & $\begin{array}{l}8.28(4.44, \\
18.38)\end{array}$ & $\begin{array}{l}64.30(21.35, \\
286.80) \mathrm{a}\end{array}$ & $\begin{array}{l}18.14(5.63 \\
57.70) \mathrm{b}, \mathrm{c}\end{array}$ & 20.533 & $<0.001$ \\
\hline $\mathrm{IL}-4, \mathrm{pg} / \mathrm{mL}$ & $\begin{array}{l}43.75(21.99, \\
67.96)\end{array}$ & $\begin{array}{l}52.19(35.78, \\
59.16)\end{array}$ & $\begin{array}{l}43.75(10.30, \\
65.42)\end{array}$ & 1.543 & 0.462 \\
\hline $\mathrm{IL}-5, \mathrm{pg} / \mathrm{mL}$ & $\begin{array}{l}2.49(1.40, \\
7.21)\end{array}$ & $\begin{array}{l}0.83(0.72 \\
1.26) \mathrm{a}\end{array}$ & $\begin{array}{l}1.23(0.87 \\
1.85) \mathrm{a}, \mathrm{c}\end{array}$ & 25.185 & $<0.001$ \\
\hline IL-6, pg/mL & $\begin{array}{l}10.92(3.74 \\
19.94)\end{array}$ & $\begin{array}{l}22.76(2.76 \\
46.12)\end{array}$ & $\begin{array}{l}19.57(7.26 \\
46.62)\end{array}$ & 4.320 & 0.115 \\
\hline IL-8, pg/mL & $\begin{array}{l}953.15(426.06 \\
1517.75)\end{array}$ & $\begin{array}{l}1307.50(701.92, \\
3757.75) \mathrm{a}\end{array}$ & $\begin{array}{l}1209.0(732.36 \\
1976.50) \mathrm{b}\end{array}$ & 9.165 & 0.010 \\
\hline
\end{tabular}




\begin{tabular}{|c|c|c|c|c|c|}
\hline $\mathrm{IL}-13, \mathrm{pg} / \mathrm{mL}$ & $\begin{array}{l}3.33(1.95 \\
8.69)\end{array}$ & $\begin{array}{l}3.39(2.14, \\
4.50)\end{array}$ & $\begin{array}{l}3.62(2.44, \\
5.64)\end{array}$ & 1.687 & 0.430 \\
\hline $\begin{array}{l}\text { IL-17A, } \\
\mathrm{pg} / \mathrm{mL}\end{array}$ & $\begin{array}{l}2.08(1.58, \\
3.18)\end{array}$ & $\begin{array}{l}3.56(2.11 \\
5.08) \mathrm{a}\end{array}$ & $\begin{array}{l}2.66(1.72, \\
4.18)\end{array}$ & 8.764 & 0.013 \\
\hline $\mathrm{MDC}, \mathrm{pg} / \mathrm{mL}$ & $\begin{array}{l}41.09(20.57 \\
75.15)\end{array}$ & $\begin{array}{l}38.58(24.70, \\
64.29)\end{array}$ & $\begin{array}{l}46.01(26.46, \\
75.14)\end{array}$ & 2.487 & 0.288 \\
\hline $\begin{array}{l}\text { Exacerbation } \\
\text { in the } \\
12 \text {-month } \\
\text { follow-up }\end{array}$ & & & & & \\
\hline $\begin{array}{l}\text { Withdraw, n } \\
(\%)\end{array}$ & $0(0)$ & $3(10)$ & $3(6.1)$ & 3.367 & 0.186 \\
\hline $\begin{array}{l}\text { Severe } \\
\text { exacerbation, } \\
\mathrm{n}(\%)\end{array}$ & $6(17.1)$ & $10(37)$ & $3(6.5) \mathrm{c}$ & 10.935 & 0.004 \\
\hline $\begin{array}{l}\text { Severe } \\
\text { exacerbation } \\
\text { times }\end{array}$ & $0.29 \pm 0.75$ & $0.70 \pm 1.33$ & $0.09 \pm 0.35 \mathrm{c}$ & 10.965 & 0.004 \\
\hline $\begin{array}{l}\text { Emergency } \\
\text { Visit, n (\%) }\end{array}$ & $3(8.6)$ & $2(7.4)$ & $2(4.3)$ & 0.636 & 0.728 \\
\hline $\begin{array}{l}\text { Emergency } \\
\text { Visit times }\end{array}$ & $0.11 \pm 0.40$ & $0.07 \pm 0.27$ & $0.09 \pm 0.41$ & 0.552 & 0.759 \\
\hline $\begin{array}{l}\text { Hospitalization, } \\
\mathrm{n}(\%)\end{array}$ & $5(14.3)$ & $5(18.5)$ & $3(6.5)$ & 2.560 & 0.278 \\
\hline $\begin{array}{l}\text { Hospitalization } \\
\text { times }\end{array}$ & $0.26 \pm 0.74$ & $0.26 \pm 0.66$ & $0.09 \pm 0.35$ & 2.513 & 0.285 \\
\hline
\end{tabular}




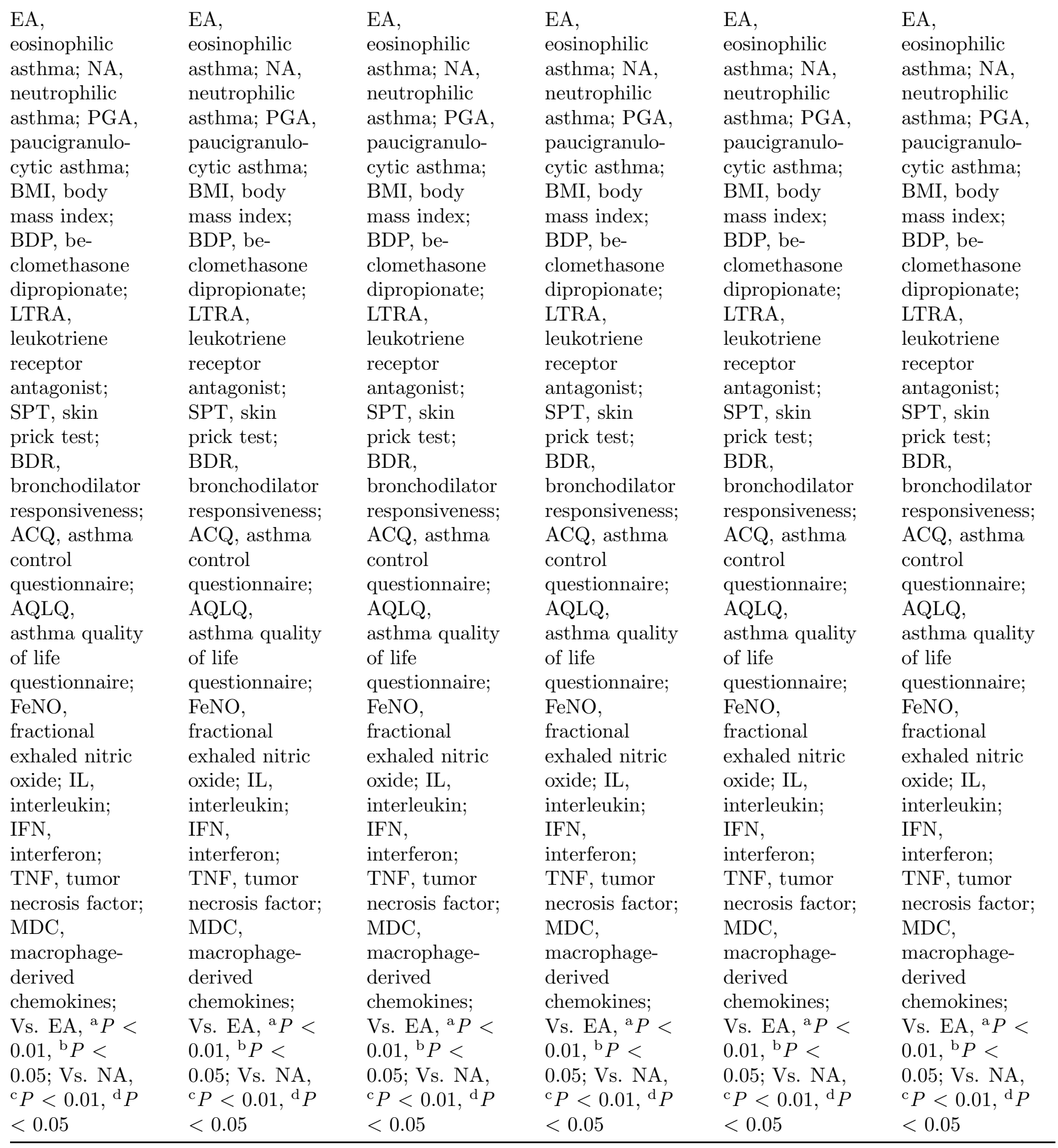

Table 2. targeted Metabolites grouped by airway inflammation phenotypes in the validation set Variables

$\mathrm{n}$ 
Diethanolamine, nmol/L

Histamine, nmol/L

Creatinine, $\mathrm{nmol} / \mathrm{L}$

Adenine, $\mathrm{nmol} / \mathrm{L}$

Acetylcholine, nmol/L

Phosphorylcholine, nmol/L

Glycerophosphocholine, $\mathrm{nmol} / \mathrm{L}$

Adenosine 5'-monophosphate, nmol/L

Pyruvate, nmol/L

Lactate, $\mathrm{nmol} / \mathrm{L}$

Glyceric acid, nmol/L

3-Hydroxyisovaleric acid, nmol/L

Taurine, $\mathrm{nmol} / \mathrm{L}$

Barbituric acid, nmol/L

Allantoin, nmol/L

5-L-Glutamyl-L-alanine, $\mathrm{nmol} / \mathrm{L}$

Arginyl-Serine, nmol/L

$\mathrm{N}$-Acetylneuraminic acid, nmol/L

Cyclohexylamine, $\mathrm{nmol} / \mathrm{L}$

Nicotinamide, nmol/L

Dihydrothymine, nmol/L

L-Leucine, nmol/L

Tyramine, nmol/L

L-Glutamate, $\mathrm{nmol} / \mathrm{L}$

Xanthine, nmol/L

L-Phenylalanine, nmol/L

Alanyl-Leucine, $\mathrm{nmol} / \mathrm{L}$

Allocystathionine, $\mathrm{nmol} / \mathrm{L}$

Salbutamol, nmol/L

Phenylalanyl-Serine, nmol/L

Threoninyl-Phenylalanine, $\mathrm{nmol} / \mathrm{L}$

Phenylalanylphenylalanine, $\mathrm{nmol} / \mathrm{L}$

Indolelactic acid, $\mathrm{nmol} / \mathrm{L}$

Dodecanoic acid, $\mu \mathrm{g} / \mathrm{mL}$

cis-9-Palmitoleic acid, $\mu \mathrm{g} / \mathrm{mL}$

Heptadecanoic acid, $\mu \mathrm{g} / \mathrm{mL}$

Stearic acid, $\mu \mathrm{g} / \mathrm{mL}$

Oleic acid, $\mu \mathrm{g} / \mathrm{mL}$

Linoleic acid, $\mu \mathrm{g} / \mathrm{mL}$

EA, eosinophilic asthma; NA, neutrophilic asthma; PGA, paucigranulocytic asthma; Vs. EA, ${ }^{\text {a }} P<0.01,{ }^{b} P<0.05$; Vs. N

Table 3. metabolites predict asthma exacerbation(Adjusted Model)

Metabolites(nmol/L)

Adenine

Phosphorylcholine

Adenosine 5'-monophosphate

Pyruvate

3-Hydroxyisovaleric acid

Allantoin
Proportions of patients experiencing severe asthma exacerbation $\mathrm{OR}(95 \% \mathrm{CI})$

$0.997(0.994,1.001)$

$1.030(0.986,1.076)$

$1.000(1.000,1.000)$

$1.000(1.000,1.000)$

$0.996(0.992,1.001)$

$1.000(1.000,1.000)$
Proportions of $\mathrm{p}$

$P$ value

0.146

0.181

0.050

0.350

0.108

0.136 
N-Acetylneuraminic acid

Nicotinamide

Tyramine

Allocystathionine

Threoninyl-Phenylalanine

Adjusted for age, gender, BMI, FEV 1
$1.000(1.000,1.000)$

$1.001(0.999,1.003)$

$1.015(0.955,1.080)$

$1.014(0.929,1.106)$

0.999 $(0.998,1.001)$

Adjusted for age, gender, BMI, FEV 1
0.125

0.248

0.626

0.756

0.558

Adjusted for age

Figure legends:

Figure 1. Untargeted metabolic profiles discriminate in different inflammatory asthma phenotypes and healthy subjects in the discovery set. (A-D) Score plot of PCA model obtained from different inflammatory asthma phenotypes and healthy subjects retrospectively; (E-H) Score plot of OPLS-DA model obtained from different inflammatory asthma phenotypes and healthy subjects retrospectively; The labels $\mathrm{t}[1]$ and $\mathrm{t}[2]$ along the axes represent the scores (the first 2 partial least-squares components) of the model, which are sufficient to build a satisfactory classification model. (I-L) Permutation Test of the OPLS-DA model obtained from different inflammatory asthma phenotypes and healthy subjects retrospectively; Two hundred permutations were performed, and the resulting $\mathrm{R}^{2}$ and $\mathrm{Q}^{2}$ values were plotted.

Figure 2. Heatmap of identified differential metabolites in sputum samples in different inflammatory asthma phenotypes and healthy subjects in the discovery set

Figure 3. MetaboAnalyst Pathway Impact based on selected and more representative metabolites responsible for the class separation in sputum samples in different asthma phenotypes and healthy subjects. (A) Asthma and Healthy; (B) EA and NA; (C) EA and PGA; (D) NA and PGA. Circles represent metabolic pathways potentially involved in class separation. EA, eosinophilic asthma; NA, neutrophilic asthma; PGA, paucigranulocytic asthma.

Figure 4. The receiver operating characteristic (ROC) curves of metabolites to discriminate between NA and EA (A) or between NA and PGA (B). EA, eosinophilic asthma; NA, neutrophilic asthma; PGA, paucigranulocytic asthma.

Figure 5. Heatmap of correlations of differential metabolites with clinical and inflammatory profiles in all subjects with asthma in the validation set

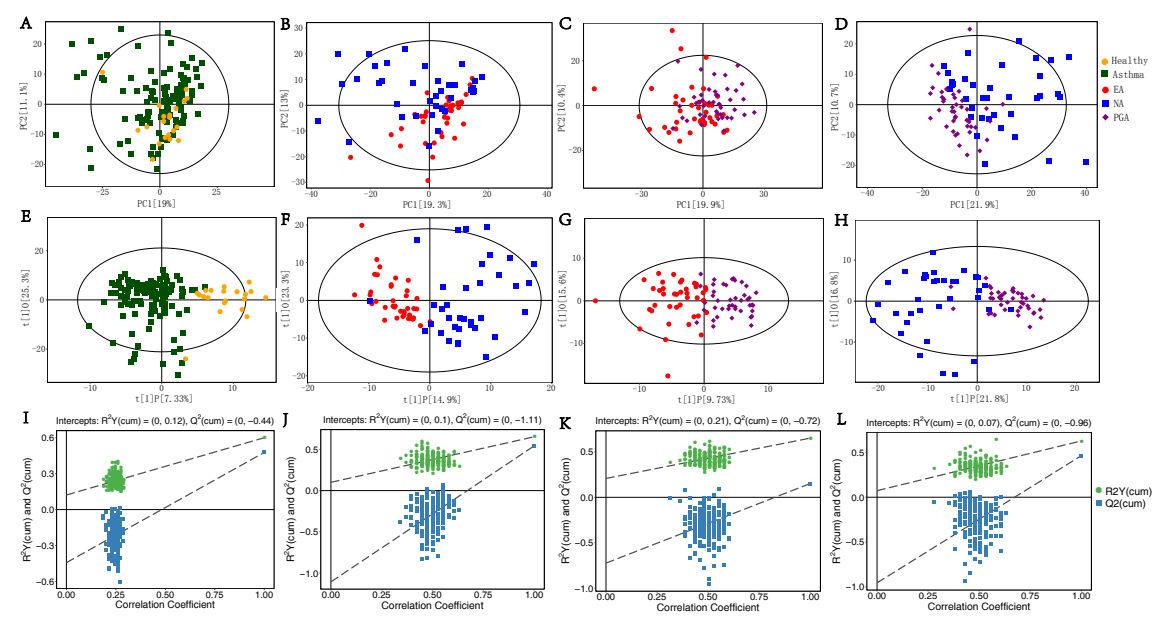



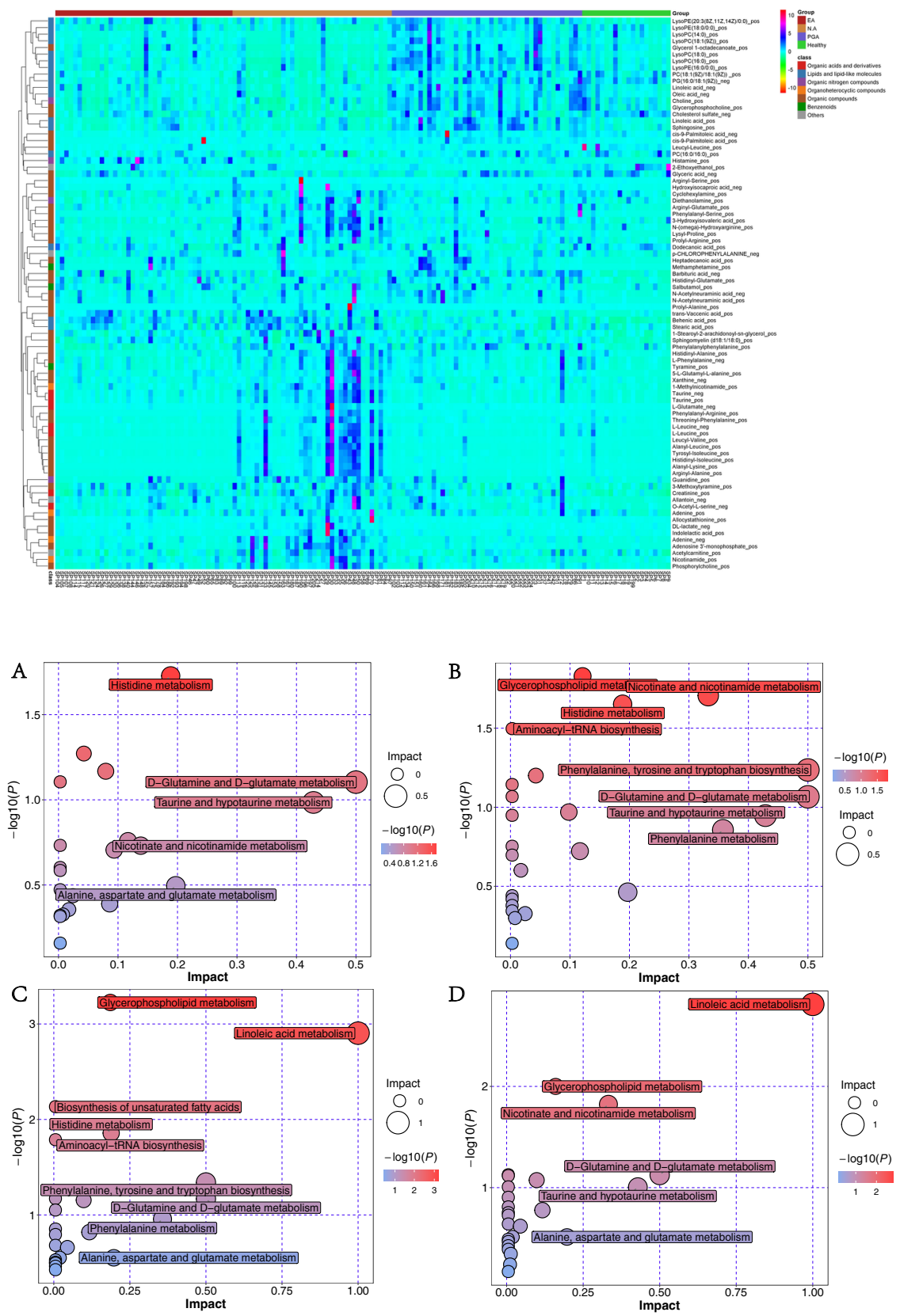

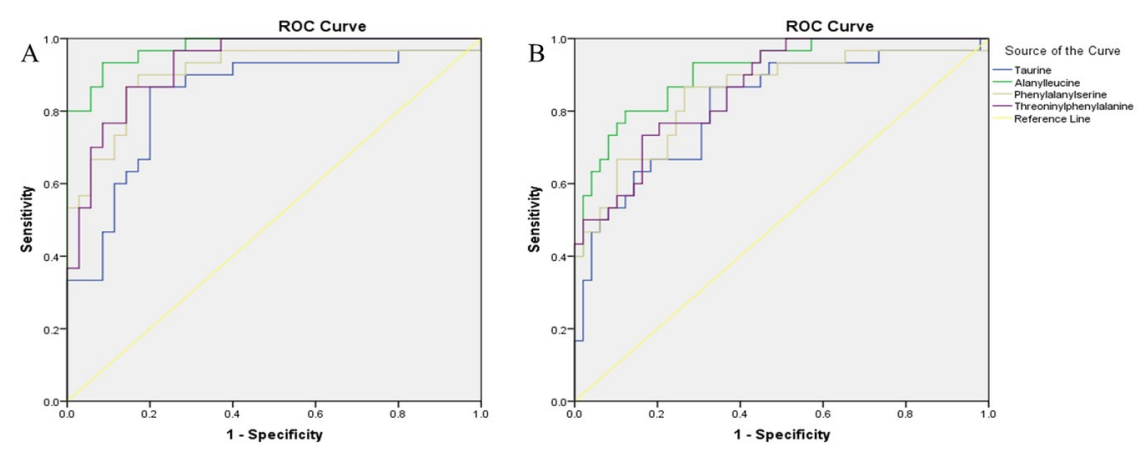


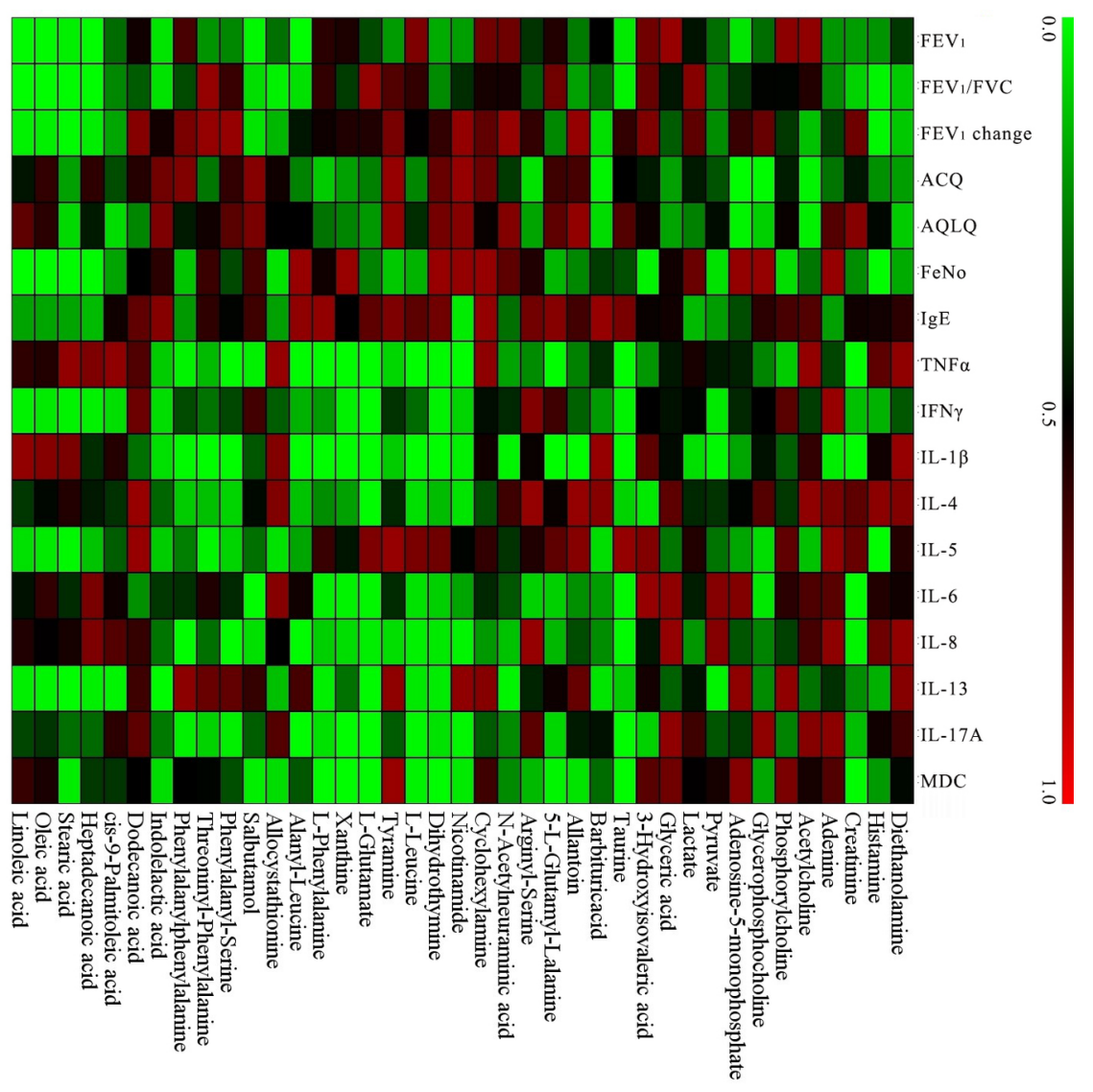

